Preyaratt Phitayakom MD, Brian M. Melnick MD, Albert F. Vicinie III HS

\title{
Comparison of con- tinuous sufentanil and fentanyl infusions for outpatient anaesthesia
}

Fifty ASA physical status class I or II patients undergoing outpatient $D \& C$ (dilatation and curetiage of the uterus) were studied. Patients were divided into two graups in a random double-blind manner and given either a fentangl bolus $0.7 \mu \mathrm{g}$. $\mathrm{kg}^{-1}$ followed by coninuous fenuanyl infusion of $0-50 \mu \mathrm{g} \cdot \mathrm{min}^{-1}$ or sufentanil bolus $0.1 \mu \mathrm{g} \cdot \mathrm{kg}^{-1}$ followed by continuous sufencanit infusion of $0-7 \mu \mathrm{g} \cdot \mathrm{min}^{-1}$ as an adjuvant to thiopentone, nitrous axide:oxygen anaesthesia. Patients were followed throughout the recovery process with respect to level of consciousness, nausea, vomiting, pain, and discharge sime. Groups were equal with respect to awakening and discharge time. The incidence of nausea $(p<0.05)$ and pain requiring analgesics $(p<0.05)$ were less in the sufentanil group. It is concluded that the technique of continuous sufentanil infusion was superior to fentanyl in healthy outpatients undergoing $D \& C$.

The volume of outpatient surgical procedures continues to grow. It is estimated that by 1990 more than 50 per cent of all surgical procedures will be performed on an outpatient basis. ${ }^{1}$ There is still controversy over which anaesthetic techniques are most appropriate. White ${ }^{2}$ has shown that when fentanyl is used as an adjuvant to nitrous oxide in oxygen, a continuous infusion is superior to an intermittent bolus technique. Sufentanil, a new narcotic agonist, is reported to be between five and ten times more potent than fentanyl. ${ }^{3,4}$ It has a more rapid onset $^{5}$ and shorter elimination half-life $e^{6,7}$ and recovery times $^{8}$ than does fentanyl. These three characteristics

\section{Key words}

ANALGESICS: sufentanil, fentanyl; ANAESTHETICS, INTRA VENOU: sufentanil, fentanyl; ANAESTHESIA: uUtpatient, recovery.

From the Department of Anesthesiology, University of Pittsburgh, School of Medicine and Magee-Women's Hospital, Pittsburgh, Pennsylvania 15213.

Address correspondence to Dr. Phitayakorn. make it an attractive alternative to fentanyl for outpatient anaesthesia.

\section{Methods}

Fifty ASA physical status class I or II patients undergoing outpatient D\&C under general anaesthesia were studied. The study was approved by the Hospital Committee on Human Experimentation and informed consent was obtained from the patients. Patients were assigned via a random number draw to the fentanyl or sufentanil group. The study was conducted in a double-blind manner. One half-hour prior to surgery a Trieger Dot test ${ }^{9}$ was administered to each patient. All patients had an 18-gauge intravenous catheter placed on the hand opposite the blood pressure cuff, and were monitored via ECG, automated blood pressure cuff (Ohio 2105), precordial stethoscope, and pulse oximeter (Nellcor). No preoperative medications were given.

All patients were induced with thiopentone, $5 \mathrm{mg} \cdot \mathrm{kg}^{-1}$ IV and maintained with nitrous oxide: oxygen, $4: 2 \mathrm{~L} \cdot \mathrm{min}^{-1}$ in semi-closed circle system. All the patients were allowed to breathe spontaneously, with manual assistance. The concentrations of the sufentanil and fentanyl solutions were adjusted to yield equipotent doses $(1: 7)$ of the respective drugs. This resulted in a fentanyl concentration of $50 \mu \mathrm{g} \cdot \mathrm{ml}^{-1}$ for bolus administration and $3.5 \mu \mathrm{g}$. $\mathrm{ml}^{-1}$ for continuous infusion. For sufentanil it was $7 \mu \mathrm{g}$. $\mathrm{ml}^{-1}$ bolus and $0.5 \mu \mathrm{g} \cdot \mathrm{ml}^{-1}$ for continuous infusion. Group I received $0.7 \mu \mathrm{g} \cdot \mathrm{kg}^{-1}$ of fentanyl IV bolus then continuous infusion at a rate of $0-15 \mathrm{ml} \cdot \mathrm{min}^{-1}$ depending upon depth of anaesthesia as determined by the investigators. Group II received $0.1 \mu \mathrm{g} \cdot \mathrm{kg}^{-1}$ of sufentanil solution IV bolus and also continuous infusion at the above rates according to perceived anaesthesia depth. No pa-

TABLE I Patient characteristics (mean + SD)

\begin{tabular}{llc}
\hline & Sufentanil & Fenamyl \\
\hline $\mathrm{n}$ & 25 & 25 \\
Age $(\mathrm{yr})$ & $45.0 \pm 9.5$ & $44.6 \pm 13.0$ \\
$\mathrm{Ht}(\mathrm{cm})$ & $163.9 \pm 5.5$ & $163.8 \pm 6.0$ \\
Wt $(\mathrm{kg})$ & $64.9 \pm 11.0$ & $61 \pm 18.5$ \\
\hline
\end{tabular}


TABLE II Results - timc faclors (mean \pm SD)

\begin{tabular}{lcc}
\hline & Sufentanil $(n=25)$ & Fentanyl $(n=25)$ \\
\hline Duration of anaesthesia (min) & $24.5 \pm 8.5$ & $23.8 \pm 7.0$ \\
First response (min) & $3.8 \pm 2.5$ (range 1-11) & $3.4 \pm 2.0$ (range $1-11)$ \\
Recovery room (min)* & $47 \pm 36.5$ & $56 \pm 20$ \\
Tolal unlil discharge home (min) & $109 \pm 35$ & $121 \quad \pm 32$ \\
\hline
\end{tabular}

*Student's t test; $\mathrm{p} \leq \mathbf{0 . 0 5}$.

tients required supplemental doses of thiopentone or bolus narcotic.

Depth of anaesthesia was evaluated by observing the patients for movement, phonation, tearing, laryngospasm, or an increase in pulse or blood pressure to greater than 25 per cent of pre-induction values. Infusion rates were adjusted as necessary based upon above indications. Following the procedure, nitrous oxide and narcotic infusions were stopped. The patients breathed 100 per cent oxygen until they responded appropriately to a command to open their eyes. The response time was determined to be the time from cessation of nitrous oxide to positive response to above command. Patients were then transferred to the recovery roon. The recovery room nurses were blinded to which study drug had been administered.

On arrival in the recovery room the patient's level of consciousness was assessed by the recovery room nurse as unconscious, sleepy, or awake, and responses were recorded as 0,1 , or 2 , respectively. Patients were ques. tioned upon arrival and then every 15 minutes as to the presence of pain or nausea. Pain wes scored as 0 for none, one for mild, and two for moderate to severe. If patients spontaneously complained of pain or nausea, or vomited, this was also recorded. If patients with pain, nausea or vomiting desired medication, they were given it by their anaesthetist's order. After patients had achieved an Aldrete ${ }^{10}$ recovery score of ten and could sit with legs dangling for five minules, they walked to the step-down area. There, the patients were seated in recliners and were observed by recovery room nurses, as indicated above, until their discharge. A repeat Trieger Dot test was administered upon arrival in the step-down area. Patients were discharged when they were ambulatory, could void, take oral fluids, dress themselves, and complete the Trieger Dot test. The patients were discharged by their anaesthetist.

Data were analyzed using Fisher's exact probability test or the Student's paired I test, as appropriate.

\section{Results}

The patient groups were comparable with respect to age, height, and weight (Table I). The mean dose of fentanyl given was $93.28 \mu \mathrm{g} \pm 4.88$ (mean \pm SEM). The mean sufentanil dose was $13.02 \mu \mathrm{g} \pm 2.35$. Assuming a potency ratio of $7: 1$ (sufentanil:fentanyl), there is no difference between these dosages. The assessed level of consciousness throughout recovery did not differ between groups. There were no significant differences between groups in the duration of anaesthesia, time to first response, time to discharge, and the results of the Trieger test, although recovery room time was slightly shorter with sufentanil (Table II). No patient was required to take more than one Trieger Dot test in the recovery room.

Patients in the fentanyl group reported more postoperative pain and a higher incidence of requested analgesia ( $p<0.05$ (Table III)). The fentanyl group also had a higher incidence of nausea during the first hour $(p<$ 0.05 ) and a higher incidence of nausea throughout the total recovery period ( $p<0.05$ (Table IV)). The groups exhibited no significant differences in the incidence of vomiting. Two patients in the sufentanil group did develop chest wall rigidity during the surgical procedure which

TABLE III Postoperative pain

\begin{tabular}{|c|c|c|c|c|c|c|c|c|}
\hline \multirow[b]{3}{*}{ Degree of pain } & \multicolumn{8}{|c|}{ Tof pasients experiencing pain } \\
\hline & \multicolumn{4}{|c|}{ Sufentonil $(n=25)$} & \multicolumn{4}{|c|}{ Fenranyl $(n=25)$} \\
\hline & Arrival & $T=I h r$ & $T=2 h r$ & Total & Arrival & $\mathrm{T}=/ \mathrm{Mr}$ & $T=2 h r$ & Total \\
\hline Mild & 0 & 0 & 0 & 0 & 0 & 16 & 12 & 16 \\
\hline Moderate-severe & 0 & 4 & 0 & 4 & 0 & 9 & 9 & 12 \\
\hline Total & 0 & $4^{*}$ & 0 & $4^{*}$ & 0 & 25 & 21 & $38^{*}$ \\
\hline \% Requiring analgesics & 0 & 4 & 0 & $4^{*}$ & 0 & 12 & 12 & $24 *$ \\
\hline
\end{tabular}

${ }^{*} p<0.05$. Fisher's exact probability test. 
TABLE IV Postoperative nausea

\begin{tabular}{|c|c|c|c|c|c|c|c|c|}
\hline & \multicolumn{8}{|c|}{ \% of patients with nausea and vomiting } \\
\hline & \multicolumn{4}{|c|}{ Sufentanil ( $n=25$ ) } & \multicolumn{4}{|c|}{ Fentanyl $(n=25)$} \\
\hline & Arrival & $T=/ h r$ & $T=2 \mathrm{hr}$ & Total & Arrival & $T=I / h r$ & $T=2 \mathrm{hr}$ & Total \\
\hline Nausea & 4 & $16 t$ & 20 & $20^{*}$ & 8 & $48 \dagger$ & 40 & $52 *$ \\
\hline Vomiting & 4 & 16 & 0 & 16 & 8 & 28 & $\emptyset$ & 32 \\
\hline \% Requiring antiemetics & 0 & 0 & 4 & 4 & 0 & 12 & 8 & 12 \\
\hline
\end{tabular}

Fisher's exact probability test. ${ }^{*} \mathrm{p}<0.05$ between 'totals'. $\mathrm{tp}<0.05$ between 'T $=1 \mathrm{hr}$ '.

required the administration of succinylcholine, $10 \mathrm{mg}$ IV. No patients in the fentanyl group developed rigidity.

\section{Discussion}

It is unclear if there is a best general anaesthetic technique for outpatient surgery. It is often thought that patients receiving fentanyl:nitrous oxide:oxygen anaesthesia have a shorter recovery time than those receiving either enflurane or isoflurane with nitrous oxide:oxygen. ${ }^{1}$ It has been shown, however, that 40 minutes after surgery there is no significant difference between the level of consciousness and state of psychomotor functioning between these three groups. ${ }^{12}$ There is less postoperative nausea following outputient $D \& C$ 's or laparoscopies ${ }^{13}$ in patients receiving potent inhalational agents rather than in patients receiving fentanyl as part of their anaesthetic maintenance. There is, however, less bleeding during pregnancy termination in patients receiving fentanyl than in patients receiving inhalational agents. ${ }^{14}$ From these, it seems that no one technique is best for all procedures, depending upon the patient and the surgical procedure. It would appear that if a fentanyl:nitrous oxide:oxygen technique is chosen, it is better to give the fentanyl via continuous infusion rather than by intermittent bolus. ${ }^{2}$

A major goal of outpatient anaesthesia should be to allow the patient to leave the hospital as quickly as possible. This involves not only a return to near normal preoperative mental and motor functioning but also a minimalization of uncomfortable side effects such as pain or nausea and vomiting.

We found no significant difference between techniques in time to awakening (appropriate response to verbal command), time to ambulation and time to discharge home. Time in the main recovery room was shorter in the sufentanil group, but the difference was only nine minutes and this is probably not clinically important. The major differences were in nausea and postoperative pain. Fifty-two per cent of the patients in our fentanyl group teported nausea during the recovery process. This is similar to the incidence reported by others using a similar technique. ${ }^{2}$ Only 20 per cent of patients in the sufentanil group reported nausea. We feel this is an important difference. Nausea is the most common postoperative complication in outpatient surgery. ${ }^{15}$ It has many possible adverse effects. Nausea may make a patient reluctant or even unable to ambulate, therefore prolonging the discharge time. Even if it does not prolong discharge time, it will decrease the quality of the ambulatory experience for the patient. Sufentanil was therefore superior to fentanyl in this very important aspect of outpatient anaesthesia. The nausea experienced by the fentanyl group was usually mild. This is evidenced by the fact that there was no difference between the groups in the incidence of vomiting or requests for antiemetics.

Pain is the second most common postoperative complication in outpatient surgery. ${ }^{15}$ In our study, intraoperatjvely administered sufentanil proved to be a better postoperative analgesic than intraoperatively administered fentanyl. This has also been reported in open heart surgery. ${ }^{16}$ Fewer patients in the sufentanil group complained of pain and fewer requested analgesics. This difference was not expected because the drugs were given in what was thought to be equianalgesic quantities. Several explanations are possible. Factors other than analgesia can influence a patient's perception of pain. Euphoria or sedation, both known narcotic side effects, can be involved. If the sufentanil group had more euphoria or sedation than the fentanyl group, they may have been less bothered by their pain and therefore not reported it. Unfortunately, our study was not designed to evaluate this. Another possibility is that sufentanil is actually more than seven times more potent than fentanyl.

Sufentanil was associated with one problem not seen with fentanyl in this study. It did cause chest wall rigidity in two patients. ${ }^{17.18}$ This was not observed with fentanyl. Chest wall rigidity can be quite serious, as it may lead to severe ventilatory impairment and hypoxaemia. Both of our patients, however, were easily relaxed with small doses of succinylcholine and no major problems occurred.

In conclusion, we compared sufentanil and fentanyl infusion as part of the anaesthetic maintenance in patients undergoing outpatient $\mathrm{D} \& \mathrm{C}$. With both techriques, the 
patients awoke quickly, were ambulatory within one hour, and were discharged to home in approximately two hours. There was no difference between the groups in these aspects. Sufentanil was associated with less postoperative nausea and pain than was fentanyl. For outpatient anaesthesia, when a narcotic based technique is desired, both fentanyl and sufentanil are effective choices but because of decreased postoperative nausea and pain we feel sufentanil is a better choice.

\section{References}

1 O'Donovan TR. The future is now. I $M$ : Wetchler BV (ed.). Anesthesia in ambulatory surgery. Philadelphia: Lippincott, 1985: 1-32.

2 White PF. Use of continuous infusion vs. intermittent bolus administration of fentanyl of ketamine during outpatient anesthesia. Anesthesiology 1983; 59: 294-300.

3 Sebel PS, Bovill JG, Fiolet $J$ et al. Hormonal effects of sufentanil anesthesia. Anesth Analg 1982; 61: 214-5.

4 Roscow $C$. Sufentanil citrate: a new opioid analgesic for use in anesthesia. Pharmacotherapy 1984; $4: 1$.

5 Flacke JW, Kripke BK, Bloor BC et al. Intraoperative effectiveness of sufentanil, fentanyl, meperidine or morphine in balaneed anesthesia: a double-blind study. Anesth Analg 1983; 62: 259-60.

$6 \mathrm{McClain}$ DA, Hug CC. Intravenous fentanyl kinetics. Clin Pharmacol Ther 1980; 28: 106-14.

7 Bovill JG, Sebel PS, Blackburn CL. Oei-Lim V, Heykants $J$. The pharmacokinetics of sufentanil in surgical patients. Anesthesiology 1984; 61: 502-6.

8 Smith NT, Dee-Silver H, Harricon WK et al. A comparison among morphine, fentanyl, and sufentanil anesthesia for open-heart surgery. Induction, eniergence, and extubation. Anesthesiology 1983; 57: A291.

9 Fishburne JI, Fulghum MS, Hulka JF, Mercer JP. General anesthesia for outpatient laparoscopy with an objective measure of recovery. Anesth Analg 1974; 53: 1-6.

10 Aldrete JA, Kroulik $D$. A postanesthetic recovery score. Anesth Analg 1970; 49; 924-34.

11 Jones $D F$. Recovery from day-case anaesthesia: comparison of a further four techniques including use of the new induction agent Diprivan ${ }^{(3}$. Br J Anaesth 1982; \$4: 629-32.

12 Azar 1, Karambelkar DJ, Lear E. Neurologic state and psychomotor function following ancsthesia for ambulatory surgery. Anesthesiology 1984; 60: 347-9.

13 Rising S, Dodgson MS, Steen PA. Isoflurane vs. fentanyl for outpatient laparoscopy. Acta Anaesthesiol Scand 1985; 29: 25] -5

14 Hackett GH, Harris MNE, Planteoin OM et al. Anaesthesia for outpatient termination of pregnancy, $\mathrm{Br} \mathbf{J}$ Anaesth $1982 ; 54 ; 865-70$
15 Burns $K$. Postoperative care and review of complications. In: Woo SW (ed.). Ambulatory anesthesia care. Boston: Little, Brown, 1982: 27-32.

16 Clark N, Liu WS, Meuleman T, Qwanikkes P, Pace NL, Suanley $T H$. Sufentanil versus fentanyl as a supplement to $\mathrm{N}_{2} \mathrm{O}$ anesthesia during general surgery. Anesth Analg $1984 ; 63: 198$.

17 Goldherg M, Ishak S, Garcia C, McKenna J. Postoperative rigidity fallowing sufentanil administration. Anesthesialogy $1985 ; 63: 199-201$.

18 Chang J, Fish $K$. Acute respiratory arrest and rigidity after anesthesia with sufentanil : a case report. Anesthesiology $1985 ; 63 ; 710-1$

Résumé

Cinquante patients ASA classe I at II devant subir une procédure de curetage et ditatation en extcrne ont été étudiées. Les patientes étaient divisées en deux groupes d'une façon randonisée et a double insu et ont reçu soit du fentanyl en bolus $0.7 \mu \mathrm{g} \cdot \mathrm{kg}^{-1}$ suivi d'une perfusion continue de fentanyl de $0-50 \mu \mathrm{g} \cdot \mathrm{min}^{-1}$ ou un bolus de sufentanil $0.1 \mu \mathrm{g} \cdot \mathrm{kg}^{-1}$ suivi d'une perfusion conrinue de sufentanil 0-7 $\mu \mathrm{g} \cdot \mathrm{min}^{-1}$ comme adjwant au thiopentone, protoxide d'azote et oxygène. Les patientes étaient suivies au cours du processus de réveil pour l'etat de conscience, nausées, vomissements, douleur et temps de congé. Les groupes étaient égaux concernant le temps de révell et de congé. Lincidence de nausées $(p<0.05)$ et des douleurs requérant des analgésiques ( $p<0.05$ ) étaient plus basses pour le groupe du sufentanil. On conclue que la technique d"administration continue de sufentanil en perfusion ést supérieure au fentanyl chez les patientes en externe en bonne santé et devant subir un curelage et dilatation. 